\title{
The paradox of age: an analysis of responses by aging Brazilians to International Affective Picture System (IAPS)
}

\section{Paradoxo etário: uma análise feita por idosos brasileiros sobre o International Affective Picture System (IAPS)}

\author{
Weyler Galvão Pôrto, ${ }^{1}$ Paulo Henrique Ferreira Bertolucci, ${ }^{2}$ Orlando Francisco Amodeo Bueno³ \\ ${ }^{1}$ Geriatric Medicine Nucleus, Associação Portuguesa de Beneficência de São Paulo, São Paulo, SP, Brazil \\ ${ }^{2}$ Behavioral Neurology Section, Department of Neurology, Escola Paulista de Medicina, Universidade Federal de São Paulo (UNIFESP), \\ São Paulo, SP, Brazil \\ ${ }^{3}$ Department of Psychobiology, Escola Paulista de Medicina, Universidade Federal de São Paulo (UNIFESP), São Paulo, SP, Brazil
}

\begin{abstract}
Objective: To explore the possible differences in subjective analysis of the emotional stimuli from the International Affective Picture System between elderly and young samples. Method: 187 elderly subjects ranked the International Affective Picture System images according to the directions from the Manual of Affective Ratings. Their scores were compared to those obtained from International Affective Picture System studies with young people. Result: There is an age-related difference in arousal and valence in the International Affective Picture System rating. The correlation between affective valence and arousal is strong, and negative for the elderly. The expected versus the observed frequency of International Affective Picture System images between elderly and young samples show a statistical difference. Conclusion: This study shows an inter-age statistical dichotomy in how elderly and young people subjectively evaluate International Affective Picture System images.
\end{abstract}

Descriptors: Evaluation; Aged; Young adult; Individuality; Imagery (psychotherapy)

\section{Resumo}

Objetivo: Explorar as possiveis diferenças nas avaliações subjetivas dos estimulos emocionais do International Affective Picture System entre idosos e jovens. Método: 187 individuos idosos avaliaram as imagens do International Affective Picture System de acordo com o Manual de Aplicação do Teste. Os escores obtidos pelos idosos foram então comparados com os escores obtidos da normatização do International Affective Picture System para jovens. Resultados: Há diferença nos niveis de alerta e valência afetiva entre idosos e jovens. Há uma forte e negativa correlação entre valência afetiva e nivel de alerta na amostra estudada. As frequências esperadas versus observadas das imagens do International Affective Picture System entre idosos e jovens mostram diferenças estatísticas. Conclusão: Este estudo mostra uma diferença interetária na avaliação de imagens do International Affective Picture System.

Descritores: Avaliação; Idoso; Adulto jovem; Individualidade; Imagens (psicoterapia)

\section{Introduction}

Emotion interferes in the declarative memory of young individuals. It also seems to interfere in the memory of the healthy elderly. However, there is evidence that these two age groups sense this phenomenon differently. Theoretically, the elderly tend to make their choices based on stereotypes, with deficits in and/or distortions of the perceptualcontextual and peripheral spatial details,${ }^{1}$ thus directly influencing the acquired mnemonic content. Also, they present differences in source attribution; distortion of content based on emotional focus; discrepancies in the judgment of valence and level of arousal; and anomalous responses of the amygdala in the face of positive and negative stimuli. There can be discrepancies between the subjective emotional report of older and younger individuals. ${ }^{2-5}$

Specific studies on the reports of affective valence and level of arousal of young and old individuals tend to suggest disagreement

\section{Correspondence}

Weyler Galvão Pôrto

Alameda Campinas, 105/114 - Jardim Paulista

01404-000 São Paulo, SP, Brazil

Phone: (+55 11) 3251-2488 Fax: (+55 11) 3251-2909

Email: weylergalvaoporto@hotmail.com

Orlando Francisco Amodeo Bueno

Department of Psychobiology, Universidade Federal de São Paulo

Rua Botucatu, 862

04023-062 São Paulo, SP, Brazil

Phone: (+55 11) 2149-0155

Email: ofabueno@psicobio.epm.br 
in the literature. Several investigations using the same material have consistently shown divergent results, not yielding clear conclusions. This difference in the emotional assessment of an image might interfere in the evaluation of emotional stimuli and influence the content of the formed memory. In general, the literature points to concordant affective judgments of pleasure and displeasure, and discordant ones as regards the level of arousal of young and elderly individuals. ${ }^{1,6,7}$

The International Affective Picture System (IAPS) 5 is an instrument that includes various visual stimuli, standardized internationally, for the study of memory and attention in humans. It comprises hundreds of images with emotional content that include practically all the aspects of daily living situations. The images are classified as to the level of arousal, affective valence and degree of dominance they elicit in the target population studied according to a scale termed the Self Assessment Manikin (SAM). The IAPS is an instrument that is easy to use and provides control over results. However, it is standardized only for young college student populations or children.

An earlier pilot project ${ }^{5}$ carried out in Brazil which included the images from IAPS and the subjective affective reports, for elderly individuals, has shown that there is a difference between the subjective affective judgments of young people. However, it was limited by statistical conditions.

In this larger study we evaluate whether the affective reports produced by a subjective evaluation of the IAPS images differ between the young people and the elderly.

\section{Method}

\section{Objectives}

To compare the scores of affective reports obtained from the elderly in their subjective evaluation of the IAPS images with regard to affective valence and level of arousal with those obtained from two seminal studies with young Brazilians and young Americans.

\section{Subjects}

The study was carried out in the city of Veranópolis-RS, which has a population of 2,200 individuals (70\% female and 30\% male) aged over 60 and is known as being one of the longest-living and most cognitively capable populations in Brazil. A logistics team of the Institute of Geriatrics and Gerontology of the Pontifícia Universidade Católica do Rio Grande do Sul (IGG-PUCRS) invited volunteers, in 2002, to participate in a study applying the IAPS to elderly individuals in Brazil. The recruitment was carried out through personal contact with the volunteers in their households and/or radio and television announcements.

In 2004, approximately 440 elderly people volunteered to participate in the study. From the total, a random sample was taken comprising 187 subjects [111 female and 76 male]. The average age of the sample was $68.3(\mathrm{SD}=6.99)$ years [mean and standard deviation] and average length of schooling was 3.0 (SD $=1.93$ ) years. All the volunteers chosen were independent as regarded the basic and instrumental activities of daily living (ADL/
IADL). They presented a performance of $6 / 6$ for ADL and of $8 / 8$ for IADL, ${ }^{8}$ and had no clinical history of cancer, or of metabolic, infectious or psychiatric disorders; cranial-encephalic trauma; loss of consciousness; abuse of illicit drugs or medications that could alter cognition. They also presented a Hachinski ${ }^{9}$ ischemic scale > of 4 . Those who wore glasses with corrective lenses and/or hearing aids were instructed in advance to wear them.

The statistical and demographic characteristics of Brazilian IAPS for young people, used for comparison, are listed at the end of this article. ${ }^{7,10}$ The tables and graphs referring to the Brazilian youngsters' IAPS evaluation can be found at http://www.unifesp. $\mathrm{br} / \mathrm{dpsicobio/adap/adapta.htm.}$

The other sample at issue here related to American youngsters and was produced originally by Lang et al. and published in $1999 .{ }^{5}$

\section{Material}

Seven hundred and two IAPS slides and the SAM scale paperand-pencil version were used according to the guidelines described in the IAPS Instruction Manual..$^{5,11-16}$ The guidelines were given in a Brazilian Portuguese version which can be found at http://www. unifesp.br/dpsicobio/adap/adapta.htm together with directions for Brazilian researchers.

\section{Procedures}

The 702 slides were presented in a counter-balanced way, in sessions involving 10 subjects at a time, organized by gender, then grouped and analyzed according to the original methodology. ${ }^{5}$ The slides were projected on a $1.5 \mathrm{~m} \times 1.8 \mathrm{~m}$ screen. Participants were placed no further than $3.5 \mathrm{~m}$ from the screen. The images were classified by means of the SAM scale according to affective valence and arousal level. The elderly persons present at the sessions rated each IAPS image according to the SAM regarding affective valence and arousal level. The total score of affective valence and arousal level for each IAPS image corresponded to the mean of the means of the 10 elderly people studied in each session. The scores were analyzed and later compared with the correspondent scores obtained in the adaptation of the IAPS for young Brazilians ${ }^{17}$ and young Americans. ${ }^{5}$ The results were then submitted to a descriptive and inferential statistical analysis aimed at finding possible differences between the affective reports of these groups. At the beginning of each session, every subject in the study individually signed an informed consent form. The UNIFESP Institutional Review Board in Research approved the protocol number CEP 438/01 (06/11/2001).

\section{Statistical analysis}

Based on the analysis of each image by the elderly subjects, we defined the mean and standard deviation according to the IAPS Instruction Manual. ${ }^{5}$ The 702 figures had equivalent mean scores of affective reports of valence and arousal to the youngsters. ${ }^{5,7,17}$ We then compared the means of the means between the elderly groups involved and then, between the elderly Brazilian sample and the young Brazilian and young American samples. The level of significance was $\left(\alpha_{2}\right) \mathrm{p}<0.05$. The Kruskal-Wallis non-parametric 
Table 1 - Mean and Standard Deviation (SD) for 702 IAPS images according to SAM scores for a Brazilian aging sample

\begin{tabular}{|c|c|c|c|c|}
\hline & \multicolumn{2}{|c|}{ Valence } & \multicolumn{2}{|c|}{ Arousal } \\
\hline & Mean & SD & Mean & SD \\
\hline Male elderly & $4.70^{*}$ & 2.92 & $5.49^{*}$ & 2.29 \\
\hline Female elderly & $5.45^{\star}$ & 2.37 & $4.96^{\star}$ & 1.96 \\
\hline Global Mean & $5.00^{\star \star}$ & 2.51 & $5.27^{\star \star \star \star}{ }^{\dagger}$ & 2.38 \\
\hline Ribeiro, $2003^{9}$ & $5.20^{\star \star}$ & 2.38 & $5.16^{\star \star \star} \dagger$ & 1.74 \\
\hline Lang et al., $1999^{5}$ & $5.24^{\star \star}$ & 1.84 & $4.92^{\star \star \star}$ & 1.22 \\
\hline
\end{tabular}

Ribeiro, 2003 and Lang et al., 1999.

$\Sigma=$ male + female elderly; ${ }^{*} p<0.05$ (Mann-Whitney); ${ }^{* *} p>0.05$ (Kruskall-Wallis); ${ }^{\star \star \star} p<0.05$ (Kruskall-Wallis); ${ }^{\dagger} p>0.05$ (MannWhitney)

analysis of variance was used in the comparison of more than two independent samples, and the Mann-Whitney test to compare two independent samples. The measures of correlation between valence and arousal were obtained by Spearman's correlation (rho).

The SAM scores were reduced to the level of nominal measurement for the analysis of frequency of the slides for all samples involved, the elderly and the youngsters. The nominal independent samples were compared by the $\chi^{2}$ method, according to the frequencies of images observed and expected between the groups.

\section{Results}

The international standard number of each IAPS image studied is presented in three tables at http://www.unifesp.br/dpsicobio/ adap/tabelas_lang.pdf. Each standard number is followed by a brief description/concept of the images, and the scores for affective valence and arousal level of each image classified for the elderly population according to the SAM scale for elderly females, elderly males and the total of both groups. The comparison of the mean scores of affective valence and arousal level for the young and the elderly people can be found in Table 1 .

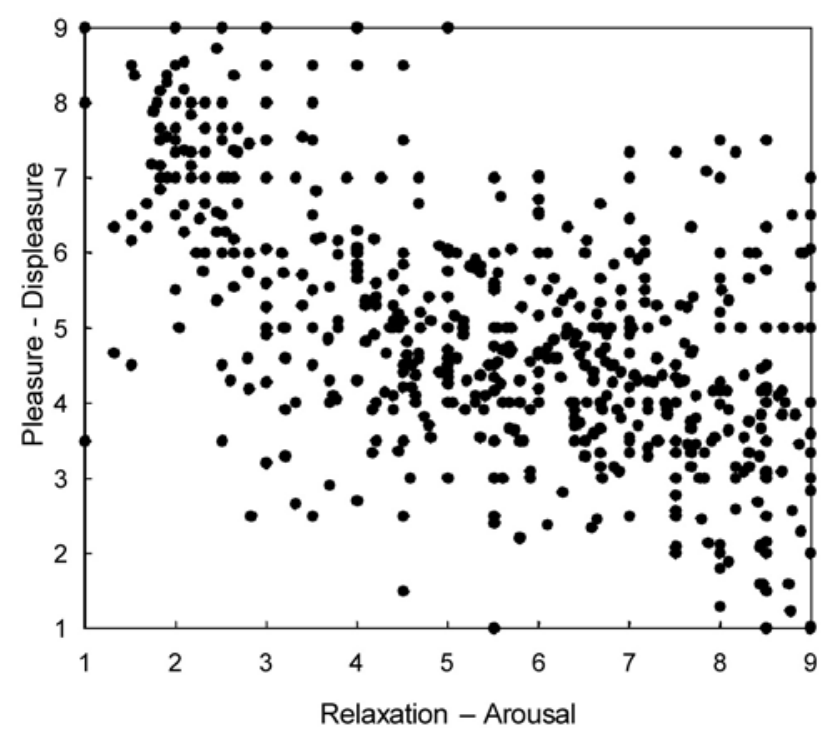

Figure 2 - Affective space obtained from the analysis of the elderly male regarding the means of the 702 images studied.

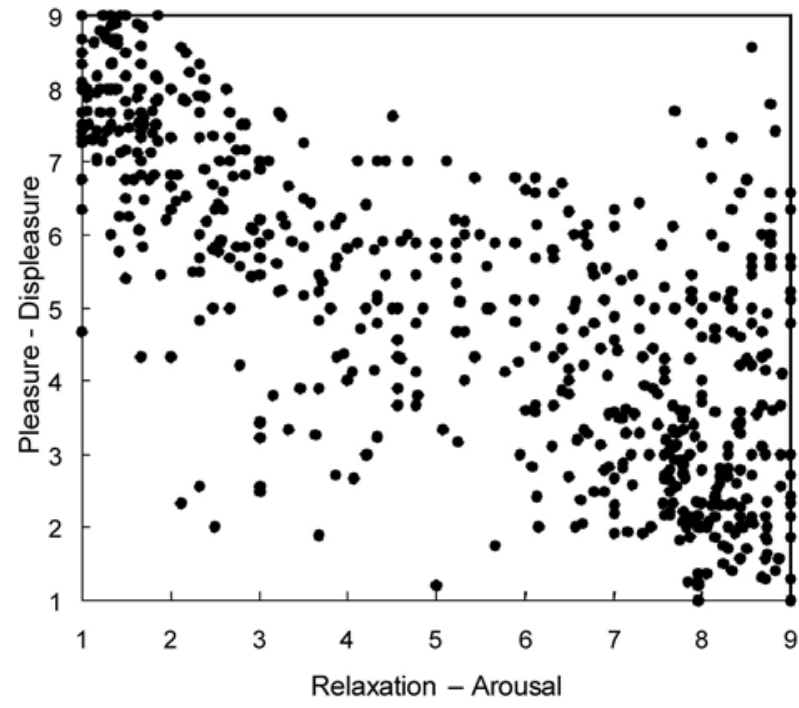

Figure 1 - Affective space obtained from the analysis of the elderly female regarding the means of the $\mathbf{7 0 2}$ images studied.

The female elderly showed a correlation between valence and arousal $\left(r_{s}=-0.8\right)$ which was greater than that for their male counterparts $\left(r_{s}=-0.66\right)$ (Figure 1 and 2$)$. The correlation between valence and arousal for the elderly males plus females is statistically significant and has a strong negative association $\left(r_{s}=-0.8 ; p<0.05\right)$ (Figure 3).

The analysis of variance of the mean scores of affective valence between the Brazilian elderly (male and female taken together) and young Brazilians ${ }^{11}$ (and the young Americans ${ }^{5}$ ) does not show statistically significant differences (Kruskal-Wallis p > 0.05), whereas the mean scores of arousal level between those groups involved do show a difference $(\mathrm{p}<0.05)$. The a posteriori analysis (Mann-Whitney) for the study of the means of arousal between the groups studied shows a statistically significant difference between Brazilian elderly and young people $(\mathrm{p}<0.05)$ [Table 1 ].

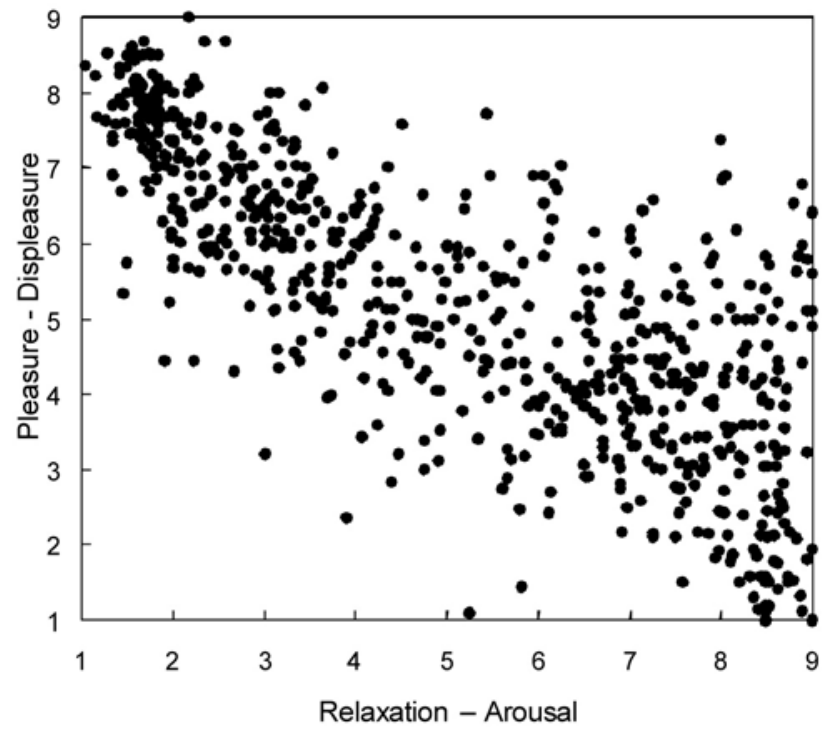

Figure 3 - Affective space obtained from the analysis of the elderly female and male together. 
Table 2 - Nominal measurement - Affective Valence

\begin{tabular}{lccc}
\hline \multicolumn{1}{c}{ Valence } & Elderly & Ribeiro, 2003 & Lang et al., 1999 \\
\hline Displeasure & 203 & 187 & 127 \\
Neutral & 201 & 225 & 303 \\
Pleasure & 298 & 290 & 272 \\
\hline
\end{tabular}

The 702 IAPS images were reduced to the level of nominal measurement so that we could group them according to their characteristic affective valence and arousal levels (Tables 2 and 3). It can be observed that the images migrate from one group to the other, changing their affective characteristic depending on the age group being studied when the frequencies are evaluated.

The frequencies observed for the elderly as regards affective valence do not present statistically significant differences when compared to the frequencies expected for young Brazilians $\left(\chi^{2} p>0.05\right)$. However, when we analyze the level of arousal, the frequencies of the elderly were statistically different from those expected for young Brazilians $\left(\chi^{2} \mathrm{p}<0.05\right)$.

\section{Discussion and conclusion}

The IAPS and the SAM were created primarily to produce a large number of standardized images that could be used as stimuli to evoke emotion and facilitate the replication and control of results in studies of emotion and attention. Each IAPS image allows for three possible SAM evaluations as regards the dimensions of affectiveness, arousal and dominance. The IAPS is generally standardized for young populations. Therefore, we hypothesize in this study that the affective reports produced by the IAPS stimuli in the elderly might yield a different subjective evaluation from that in young people. The results of the IAPS adaptation for the elderly in this study reinforce this possibility. The frequency of affective reports regarding the level of arousal conveyed by the IAPS images differs between the young and the elderly Brazilians. The same does not happen, however, in relation to affective valence.

The scores for affective valence and arousal can be displayed in a dispersion graph for the statistical analysis of correlation and for the determination of the affective pattern of a given group. The dispersion graph is also referred to as a "bi-dimensional graph of affective space" or simply "affective space" ${ }^{12}$ Differences in the shape of the affective space can be observed as a result of distinct variables such as cultural differences, age, psychopathies or brain lesions. ${ }^{17,18}$ The norms for the elderly obtained three figures of affective space. Figures 1 and 2 show respectively the affective space of elderly females and elderly males. Figure 3 presents the affective space of both males and females. All the three figures of affective space have a negative linear and statistically significant correlation. Consequently, we can assume that the arousal level obtained by the elderly tends to increase as pleasure decreases. In a general way, we can state that the figure for affective space obtained by the elderly in the IAPS evaluation is not very different from that of young Brazilians. ${ }^{10,17}$
Table 3 - Nominal measurement - Arousal Level

\begin{tabular}{cccc}
\hline Arousal level & Elderly & Ribeiro, 2003 & Lang et al., 1999 \\
\hline Arousal & 263 & 264 & 131 \\
Neutral & 349 & 386 & 509 \\
Relaxation & 90 & 52 & 62 \\
\hline
\end{tabular}

The tendency for elderly individuals to present a negative association between these two dimensions, as shown here, is compatible with the results of a brief seminal work published in the USA ${ }^{1,5}$ and it confirms another earlier and shorter pilot study carried out by our group. ${ }^{7}$ It seems that, above all, depending on the age group studied, the figures from IAPS can migrate and change their affective characteristics. One could sum it up by saying that which represents arousal for the elderly may not be so for the young. The same is not true for valence, however, in this study.

If we consider the results we have here, our findings point to a strong impact on the way the elderly might emotionally see and cognitively analyze the environment. Emotions can be measured in terms of behavioral and physiological variables, as well as oral reports. The oral dimension of valence and arousal measured by the SAM in this work might be directly related to the behavior of the individual and the intensity of his/her respective physiological responses. ${ }^{14}$ The extent to which a healthy individual reports feeling pleasure or displeasure, or being alert or relaxed, is the direct result his/her behavior or physiological responses. ${ }^{19}$ Accordingly, positive affective valence has a behavioral relationship with the presence of a source stimulus, or its absence in the case of a negative valence. On the other hand, the arousal level represents the strength, the vigor, with which the individual either approaches the source stimulus or backs away from it (whether it is positive or negative in its intrinsic affectiveness). Emotion, or emotional evaluation, defined here as a complex biological phenomenon that develops from functional behaviors, would facilitate the survival of individuals and species and, therefore, control activity related to human survival. ${ }^{15}$ Consequently, if we analyze the results of the graphs of affective space of the elderly, we might assume that relaxing events would not be very important, or might even be redundant, when environmental mechanisms for survival are considered, which would give them low priority when compared to negative or unpleasant stimuli. The latter would indeed determine the behavior of the elderly. ${ }^{16}$

In addition to possibly influencing the behavior of an individual, as suggested above, the arousal level also activates the relation with the content of the memory formed. It is widely recognized that arousal stimuli can reinforce the mnemonic trace. ${ }^{20}$ On the other hand, explicit, contextual and spatial memories, in situations of extreme arousal, might be peripherally impaired, keeping central information clear and vivid, ${ }^{21}$ which might in principle be conflicting. In both cases, though, there is no doubt that the arousal level might affect memory. Hence, it is reasonable to expect that the memory of the elderly might also be altered by the way 
they perceive the environment. The best predictor of memory is the arousal level, and not the affectiveness of the stimulus. As demonstrated in Figures 1,2 and 3 on the affective space, the highest arousal level of the elderly is determined by negative stimuli. ${ }^{16}$ The literature points to the fact that emotion plays a central role in the daily activities of the elderly. As they judge with emotion (or a high level of arousal brought about mainly by negative stimuli) they may wrongly attribute the source and/or content of any information. Along with this hypothesis, there is also the possibility that there might be a positive bias in the declarative memory of the elderly. According to this line of thought, it is plausible to believe that the elderly are on a higher plane of organic alertness than the young individuals, so that the same negative stimuli, rather than reinforcing the mnemonic trace, as in the case of young individuals, would cause a contextual and spatial peripheral loss and a stronger focus on the central idea of the situation. Fragmenting the information could, in fact, cause a bias of positive recall. The positive and neutral stimuli of the IAPS elicit lower levels of arousal, which would enhance a smaller fragmentation of peripheral information, essential in the construction of memory sources and content. ${ }^{6,22-25}$ Even though it is tempting to take this fact for granted, controlled studies should be considered.

In conclusion, the adaptation of the IAPS for the elderly population showed a difference between the distribution of the affective space of the elderly and that of Brazilian youth, showing an inter-age difference in the subjective perception of emotions. Moreover, migrations of the IAPS stimuli were observed among the different age groups studied: that is, what represents pleasure or displeasure for the young might not be the same for the elderly.
More importantly, the same is true regarding those slides that carry a content of arousal and relaxation. Therefore, studies that involve emotion and attention should have adequate stimuli for different age groups, thus preventing bias in the final results of the research. As we have already demonstrated, all the results mentioned in the introduction might yield different conclusions should the material (adaptation of the IAPS for the elderly) be adequate to this age group. If we respect variables such as time of exposure to the emotional stimulus and affective concepts regarding arousal and valence, the emotional memory of the elderly might, in contrast to what has been shown so far, not be so different from the emotional memory of the young. Researchers might also confirm relative gains such as a positive bias in the formation of the emotional memory that would rule out, once and for all, the concept according to which old age is synonymous with loss.

We emphasize the necessity to have as much control as possible over the sample variables. A gold standard is desirable. One limitation of the study here presented was that we did not access the subjects' symptoms of depression or anxiety, apart from the strong selection quoted in the material and methods listed above. This omission could be addressed in future studies.

\section{Acknowledgements}

There is no conflict of interest involved in the production of this study. We would hereby like to thank Rafaela Larsen Ribeiro, PhD, Emilio Hideyuki Moriguchi, PhD, Yukio Moriguchi, PhD, and the city of Veranópolis in Brazil.

\section{Disclosures}

\begin{tabular}{|c|c|c|c|c|c|c|c|}
\hline $\begin{array}{l}\text { Writing group } \\
\text { member }\end{array}$ & Employment & $\begin{array}{l}\text { Research } \\
\text { grant }^{1}\end{array}$ & $\begin{array}{l}\text { Other research grant or } \\
\text { medical continuous } \\
\text { education }\end{array}$ & $\begin{array}{l}\text { Speaker's } \\
\text { honoraria }\end{array}$ & $\begin{array}{c}\text { Ownership } \\
\text { interest }\end{array}$ & $\begin{array}{l}\text { Consultant/ } \\
\text { Advisory } \\
\text { board }\end{array}$ & Other $^{3}$ \\
\hline $\begin{array}{l}\text { Weyler Galvão } \\
\text { Pôrto }\end{array}$ & $\begin{array}{c}\text { Associação } \\
\text { Portuguesa de } \\
\text { Beneficência } \\
\text { de São Paulo }\end{array}$ & $\begin{array}{l}\text { AFIP** } \\
\text { CAPES }^{\star *}\end{array}$ & - & - & - & - & - \\
\hline $\begin{array}{l}\text { Paulo Henrique } \\
\text { Ferreira } \\
\text { Bertolucci }\end{array}$ & UNIFESP & $\begin{array}{c}\text { AFIP* } \\
\text { CAPES* }^{*}\end{array}$ & $\begin{array}{l}\text { Novartis }^{\star \star} \\
\text { Janssen }\end{array}$ & $\begin{array}{l}\text { Novartis }^{\star \star} \\
\text { Janssen }\end{array}$ & $*$ & $*$ & $*$ \\
\hline $\begin{array}{l}\text { Orlando } \\
\text { Francisco } \\
\text { Amodeo Bueno }\end{array}$ & UNIFESP & $\begin{array}{l}\text { AFIP }^{\star \star} \\
\text { CAPES }^{\star \star}\end{array}$ & - & - & - & - & - \\
\hline \multicolumn{8}{|c|}{$\begin{array}{l}\text { * Modest } \\
\text { ** Significant } \\
\text { ** Significant: Amounts given to the author's institution or to a colleague for research in which the author has participation, not directly to the } \\
\text { author. } \\
\text { Note: UNIFESP = Universidade Federal de São Paulo; AFIP = Associação Fundo de Incentivo a Psicofarmacologia; CAPES = Coordenação de } \\
\text { Aperfeiçoamento de Pessoal de Nivel Superior. } \\
\text { For more information, see Instructions for Authors. }\end{array}$} \\
\hline
\end{tabular}




\section{References}

1. Denburg NL, Buchanan TW, Tranel D, Adolphs R. Evidence for preserved emotional memory in normal elderly persons. Emotion. 2003;3(3): 239-54.

2. Mather M, Johnson MK. Choice-supportive source monitoring: do our decisions seem better to us as we age? Psychol Aging. 2000;15(4):596-606.

3. Mather M, Carstensen LL. Aging and attentional biases for emotional faces. Psychol Sci. 2003;14(5):409-15.

4. Charles ST, Mather M, Carstensen LL. Aging and emotional memory: the forgettable nature of negative images for older adults. J ExpPsychol Gen. 2003;132(2):310-24.

5. Lang PG, Bradley MM, Cuthbert BN. International Affective Picture System (IAPS): Instruction manual and affective ratings - technical report A4. The center for research in psychophysiology, University of Florida: Gainsville; 1999.

6. Mather M, Canli T, English T, Whitfield S, Wais P, Ochsner K, Gabrieli JD, Carstensen LL. Amygdala responses to emotionally valenced stimuli in older and younger adults. Psychol Sci. 2004;15(4):259-263.

7. Porto WG, Bertolucci PHF, Ribeiro RL, Bueno, OFA. Um estudo dos relatos afetivos subjetivos a estímulos do International Affective Picture System em uma amostra geriátrica brasileira. Rev Psiquiatr Rio Gd Sul. 2008;30 (2):131-8.

8. Lawton MP,Brody EM. Assessment of older people: self-maintaining and instrumental activities of daily living. Gerontologist. 1969;9:179-186.

9. Hachinski VC, Iliff LD, Zihla E, Du Boulay GH, McAllister VL, Marshall J, Russell RW, Symon L. Cerebral blood flow in dementia. Arch Neurol. 1975;32(9):632-7.

10. Ribeiro RL, Pompéia S, Bueno OFA. Comparison of Brazilian and American norms for the International Affective Picture System (IAPS). Rev Bras Psiquiatr. 2005;(3):208-15.

11. Bradley MM, Lang PJ. Measuring emotion: the self-assessment manikin and the semantic differential. J Behav Ther Exp Psychiatry. 1994;25(1):49-59.

12. Lang PJ, Greenwald MK, Bradley MM, Hamm AO. Looking at pictures: evaluative, facial, visceral, and behavioral responses. Psychophysiology. 1993;30(3):261-73.

13. Cuthbert BN, Bradley MM, Lang PJ. Psychophysiological responses to affective slides across the life span (Abstr). Psychophysiology. 1988;25(4):441.

14. Lang PJ, Bradley MM, Cuthbert BN. Emotion, attention, and the startle reflex. Psychol Rev. 1990;97(3):377-395.

15. Bradley MM, Lang PJ. Measuring emotion: Behavior, feeling, and physiology. In: Lane RD, Nadel L, editors. Cognitive neuroscience of emotion. New York: Oxford University Press; 2000. p.242-76.

16. Bradley MM, Greenwald MK, Petry MC, Lang PJ. Remembering pictures: pleasure and arousal in memory. J Exp Psychol Learn Mem, Cogn. 1992;18(2):379-90.

17. Ribeiro RL. Avaliação de relatos subjetivos e de alteraçôes fisiológicas a estímulos do "International Affective Picture System" (IAPS) em estudantes universitários brasileiros [tese]. São Paulo: Universidade Federal de São Paulo, Escola Paulista de Medicina, São Paulo; 2003.

18. Bradley MM. Emotion and motivation. In: Cacioppo JT, Tassinary LG, Berntson GG, editors. Handbook of psychophysiology. Cambridge: Cambridge University Press; 2000. p.602-42.

19. Cook EW 3rd, Melamed BG, Cuthbert BN, McNeil DW, Lang PJ. Emotional imagery and the differential diagnosis of anxiety. J Consult Clin Psychol. 1988;56(5):734-40.

20. Cahill L, McGaugh JL. A novel demonstration of enhanced memory associated with emotional arousal. Conscious Cogn. 1995;4(4):410-21.

21. Christianson S, Loftus EF. Memory for traumatic events. Appl Cogn Psychol. 1987;1:225-39.

22. Carstessen LL, Charles ST. Emotion in the second half of life. Curr Dir Psychol Sci. 1998;7(5):144-9.

23. Mather M, Johnson MK. Affective review and schema reliance in memory in older and younger adults. Am J Psychol. 2003;116(2):169-89.

24. Mather M, Johnson MK, De Leonardis DM. Stereotype reliance in source monitoring: Age differences and neuropsychological test correlates. Cognit Neuropsychology. 1999;16(3/4/5):437-58.

25. Reisberg D, Hertel P. Memory and emotion. New York: Oxford University Press; 2004. p.3-413. 